\title{
puente en la autopista Barcelona La Junquera España
}

A

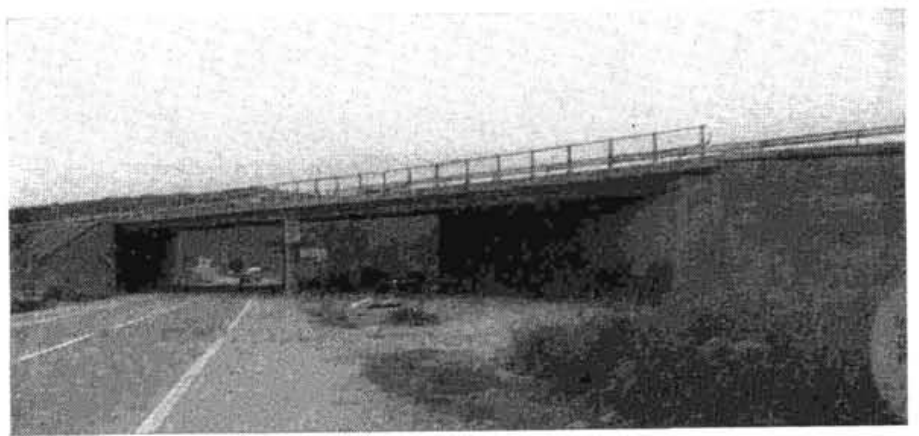

JOSE ANTONIO LLOMBART, ingeniero de caminos

$562-143$

\section{sinopsis}

La construcción de la Autopista Barcelona. La Junquera ha precisado la realización de un puente sobre la CN-II, $\mathrm{km}$ 773, al norte de Figuteras geométricas impuestas por el cruce de las dos vias de circulación y la favorable conjunción de una serie de fac. tores, han determinado la adopcion de una singular solucion encaminada a proporcionar ciertas cualidades funcionales, econó. micas y estéticas que rara vez pueden obtenerse simultaneamente en obras de este
tipo.

\section{EMPLAZAMIENTO Y DESCRIPCION GENERAL DE LA OBRA}

Características geométricas de trazado.

La Autopista A-17 discurre mediante una curva circular en planta de $1.300 \mathrm{~m}$ de radio, en la zona de paso sobre la Carretera Nacional, siendo el ángulo de cruce de los ejes de am- bas vias, ligeramente inferior a los $30^{\circ}$. La Autopista, situada sobre un terraplén, describe asimismo una curva vertical con su punto más alto situado precisamente sobre la carretera. La obra de fábrica permite el paso de la Carretera Nacional prevista con doble calzada, estando actualmente constituida por calzada simple.

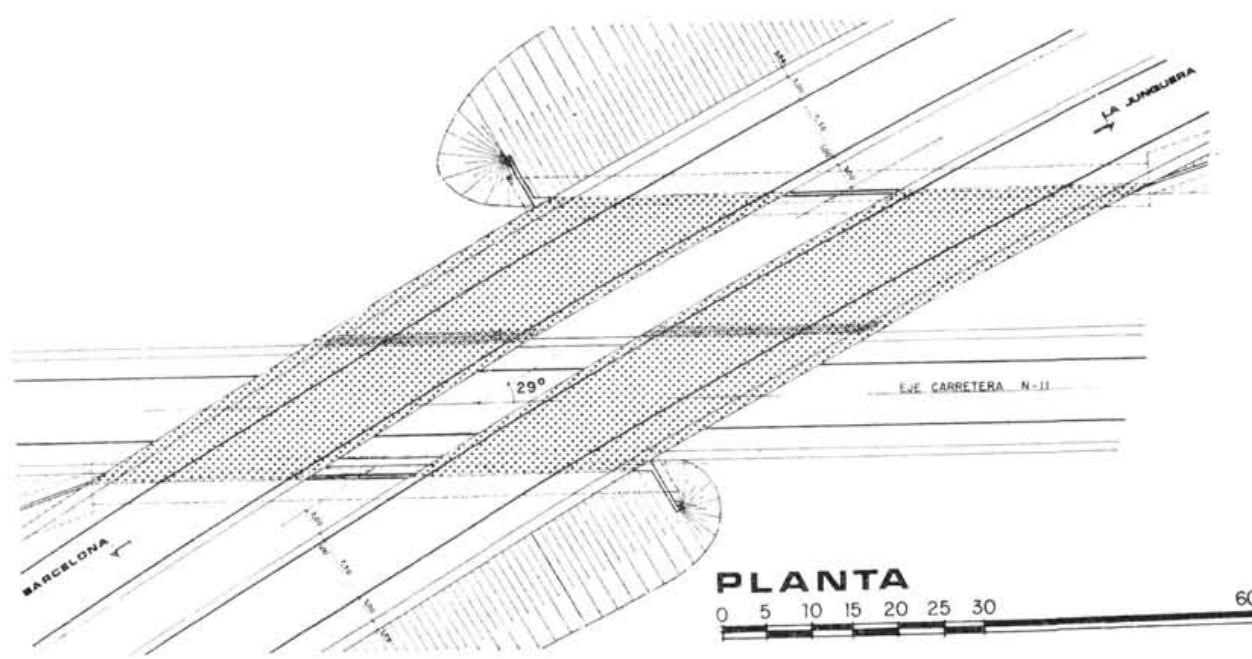




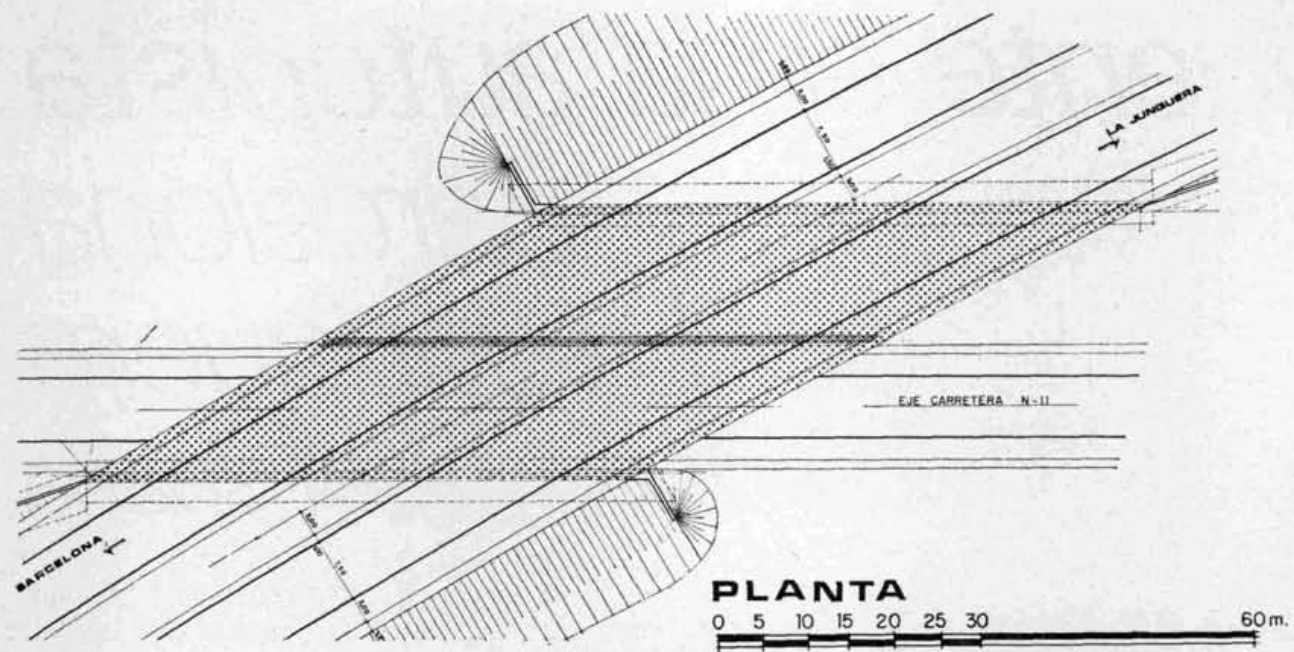

Las condiciones geométricas iniciales previstas por el trazado (fig. 1) exigían la construcción de dos estructuras gemelas de dos vanos cada una, con un espacio libre entre los bordes de los respectivos tableros, igual a $6 \mathrm{~m}$. El espesor previsto para el tablero resistente era de $1,40 \mathrm{~m}$; perfectamente compatible con las luces libres, comprendidas entre 31 y $32 \mathrm{~m}$; con lo que resultaba un gálibo útil de $5 \mathrm{~m}$ para la Carretera Nacional.

Las consideraciones estructurales que se exponen más adelante motivaron la construcción del tablero mediante una losa de $80 \mathrm{~cm}$ de espesor, que ocupaba la totalidad de la superficie requerida por la Autopista más el espacio libre previsto entre las dos calzadas (fig. 2). A fin de conseguir una superficie continua en el trasdós del tablero, se modificó la rasante de una calzada de la Autopista, bajándola en $50 \mathrm{~cm}$, sin que ello constituyese inconveniente alguno, aportándose, sin embargo, ligeras ventajas; por una parte se suavizó el acuerdo vertical de la calzada modificada; el gálibo útil de la carretera quedó ligeramente aumentado $(5,10 \mathrm{~m})$, dado el reducido espesor del tablero adoptado $(0,80 \mathrm{~m})$, y se redujo además el volumen previsto del terraplén, así como parte de los elementos verticales de hormigón de la obra de fábrica.

\section{TABLERO}

\section{Elección de la solución estructural}

El fuerte esviaje de la futura obra de fábrica nos obligó a realizar ciertas consideraciones sobre el comportamiento estructural del table- ro, a fin de conseguir una solución económica que permitiese reducir la luz mecánica, frente a la luz libre que resultaba ser del orden de $31 \mathrm{~m}$ para cada uno de los vanos que salvaban las calzadas de la Carretera Nacional.

Con el objeto de lograr la reducción deseada en los esfuerzos del tablero, consideramos primeramente la acción debida al peso propio. Un tablero realizado con vigas prefabricadas enlazadas posteriormente a su colocación en obra con una losa superior, no podía beneficiarse de la circunstancia propia del esviaje. ya que sus deformaciones debidas al peso propio se realizarían sin que existiese interacción entre vigas, es decir, que un puente esviado, construido de dicha forma, se comportaría bajo el peso propio como si se tratase de un puente recto de idéntica luz libre.

Con objeto de poder considerar el esviaje a efectos de peso propio, determinamos la conveniencia de realizar el tablero con una losa de espesor uniforme hormigonada in situ, que estructuralmente se iba a comportar como esviada desde el momento de su descimbrado, bajo el efecto de su peso propio.

Entre los distintos parámetros que determinan los esfuerzos de una losa esviada, tiene especial importancia la relación ancho de apoyoluz libre. Si construyésemos los tableros de forma que ocupasen únicamente la superficie mínima necesaria para la Autopista, la relación antedicha sería del orden de 0,80 , con lo que las estructuras no se beneficiarian apenas en la reducción de la luz mecánica debida al esviaje. 
Dada la posibilidad de ocupar mediante una losa el espacio correspondiente a la mediana la relación ancho de apoyo-luz libre pasaba a ser del orden de 2. Aunque ello representaba un aumento en la superficie de tablero construida, nos veíamos beneficiados con una considerable reducción en los esfuerzos, ya que prácticamente la zona central de la losa se comportaba mecánicamente como si su luz fuese la distancia entre los apoyos medida sobre la perpendicular, es decir, del orden de la mitad de la luz libre. Los esfuerzos máximos, localizados en los bordes, determinaban el espesor de la losa que se dispuso de $80 \mathrm{~cm}$, consiguiéndose una esbeltez de $1 / 40$ si se relaciona dicho espesor con cada una de las luces libres.

Finalmente se determinó la conveniencia de establecer la continuidad entre los dos vanos a salvar, por precisar menos armadura que la solución equivalente formada por dos losas gemelas simplemente apoyadas. Con ello existían únicamente juntas de rodadura sobre los estribos. El hecho de existir un sólo apoyo en el centro prácticamente lineal, dio la posibilidad de disponer un pórtico de diez vanos, con un dintel de escasa anchura, solicitado fundamentalmente por cargas verticales coincidentes con su eje.

\section{Losa de tablero de hormigón armado}

Un aspecto fundamental de la solución fue la elección del hormigón armado para constituir la losa. Los conceptos estructurales descritos anteriormente justificaban la disposición de una losa única para resolver el tablero, dadas las ventajas manifiestas relativas a la economía de acero y a la esbeltez conseguida, sin embargo cabía considerar la posibilidad y conveniencia de realizar la misma estructura en hormigón pretensado.

Admitidos los conceptos estructurales antedichos, en el caso de resolver la losa con hormigón pretensado, quedaría inmediatamente descartada cualquier solución en que todos los cables principales discurriesen paralelos a los bordes libres. El estudio de la influencia de la acción del pretensado sobre la losa resultaría sencillo y la deformación por dicho efecto sería cilíndrica, sin embargo la solución no tendría ventajas desde el punto de vista económico, ya que bajo la acción del peso propio, combinada con la del pretensado la losa tendería, por así decirlo, a trabajar según la luz libre; del orden del doble de la luz medida sobre la perpendicular a los apoyos.

La solución idónea debería ser, pues, orientar el pretensado según las direcciones determinadas por el funcionamiento mecánico de la estructura, es decir, con un grupo de cables paralelos a los bordes a lo largo de unas fajas relativamente estrechas y complementando el resto de la superficie con cables perpendiculares a la línea de apoyos, debiendo añadirse además las correspondientes zonas de transición. Esta solución, que podría parecer perfecta desde el punto de vista teórico, tendría inconvenientes a la hora de su realización. Por una parte, existirían grandes dificultades en el proceso de cálculo para determinar con precisión suficiente la influencia de la acción del pretensado sobre la losa. La necesidad de dicha precisión está motivada por una de las características fundamentales del hormigón pretensado, que en este caso concreto representa un inconveniente: una estructura de hormigón pretensado en clase I se comporta prácticamente como un cuerpo elástico bajo cargas instantáneas $\mathrm{y}$, por tanto, con mucha menor capacidad de redistribución que otra equivalente de hormigón armado. Era necesario tener en cuenta que dada la gran superficie de la losa (del orden de los $2.000 \mathrm{~m}^{2}$ ) y la longitud de las zonas de apoyos $160 \mathrm{~m}$ cada una), era imposible garantizar un asiento uniforme en todas sus partes. El hormigón armado ofrecía la posibilidad de adaptación de la pieza ante cualquier deformación anómala de los apoyos.

Por otra parte, el hormigón pretensado exigiría un cálculo exacto y riguroso, ya que cualquier desviación o simplificación conduciría a la aparición de esfuerzos no previstos motivados por el pretensado y se dejarían sentir inmediatamente sus consecuencias, dadas las características de elasticidad del material. El estudio de la influencia del pretensado en la losa, hoy día inabordable mediante un procedimiento analítico, resultaría extraordinariamente complicado, caso de realizarlo mediante el auxilio del computador electrónico, dada la profusión de elementos necesarios a introducir. Este estudio, posible en estructuras de menor envergadura, no podría ampliarse a este caso concreto, dada la complejidad del sistema de cables a disponer. Ello podría ser llevado a cabo únicamente en el caso de disponer de un programa perfectamente puesto a punto que permitiese desarrollar el método de los elementos finitos introduciendo el preten- 
sado sin simplificaciones que pudiesen alterar la representatividad y exactitud de los resultados.

Debe añadirse, finalmente, un inconveniente propio del pretensado que normalmente no se manifiesta en piezas lineales: las posibilidades del proyectista son limitadas en to que se refiere a concentrar cables de pretensado en zonas de esfuerzos localizados, aligerando otras partes de la estructura en que se precisa menor cantidad de acero, dada la sección constante en cada cable, cuya longitud en la práctica no debe rebasar unos valores mínimos que resultan muy superiores a los que pueden adoptarse en barras para hormigón armado.

En una losa esviada de dos vanos, la variación de los momentos, en magnitud y dirección, es considerable a lo largo de las distintas zonas. El hormigón armado ofrece la posibilidad de disponer barras de distintas longitudes, concentrarlas o aligerarlas según las exigencias originadas por los esfuerzos, aprovechando íntegramente la capacidad mecánica de las barras dispuestas, lo que no ocurre con cables de pretensado por los motivos apuntados anteriormente.

Se adoptó, pues, el hormigón armado para constituir la losa de tablero, al ser considerado como más ventajoso que el hormigón pretensado para este caso concreto.

\section{Proceso constructivo de la losa de tablero}

Dada la naturaleza monolítica de la losa de tablero y sus dimensiones, fue necesario adoptar ciertas precauciones para su construcción. El volumen total de hormigón a colocar era del orden de $1.600 \mathrm{~m}^{3}$, la longitud máxima de la zona de apoyos sobre los estribos próxima a los $70 \mathrm{~m}$ y la distancia relativa entre los ángulos agudos de la losa igual a $121 \mathrm{~m}$.

Se fraccionó el hormigonado en seis zonas, con el objeto de evitar los efectos de la retracción, así como para facilitar la puesta en obra del hormigón (fig. 3). El hormigonado de cada una de las zonas, con un volumen de unos $250 \mathrm{~m}^{3}$, se realizó en una jornada completa de 10 horas, distanciándose el hormigonado entre zonas contiguas en un mínimo de 10 días.
Las juntas de construcción se dispusieron en zonas en que las armaduras formaban un sistema ortogonal, de forma que cada junta quedaba atravesada por un solo conjunto de armaduras paralelas, con lo que el paso de las barras a través de los encofrados resultaba relativamente sencillo (fig. 4).

La dosificación del hormigón se estudió de forma que garantizase simultáneamente una mínima retracción y una manejabilidad compatible con su fácil puesta en obra mediante bombas. La resistencia característica exigida a los 28 días fue de $300 \mathrm{kp} / \mathrm{cm}^{2}$.

A fin de evitar la fisuración en el hormigón de temprana edad, debida a la retracción, se extremaron las precauciones en el curado, extendiéndose un producto impermeabilizante en la superficie superior de hormigón a medida que se realizaba su acabado.

En la figura 5 se aprecia una vista de conjunto de la obra desde un ángulo agudo del tablero. En primer término, el encofrado sin armaduras; en el centro, colocación de ferralla, y, al fondo, pueden verse las plumas de las dos bombas efectuando ya el hormigonado de la primera zona. La figura 6 muestra un detalle del hormigonado.

Se dispuso una cimbra en la totalidad de la superficie del tablero, ocupando la calzada existente de la Carretera Nacional, siendo preciso desviar ésta. Ello no representó inconveniente, ya que pudo aprovecharse como desvío provisional una carretera que discurría sobre un puente antiguo existente sobre un pequeño río cercano que era necesario cruzar (fig. 7).

\section{Armaduras de la losa de tablero}

Las armaduras se proyectaron de forma que no se precisasen empalmes por soldadura. La mayor parte de las barras se dispusieron con longitudes de $12 \mathrm{~m}$, de acuerdo con las características normales de suministro, existiendo solapes únicamente en la armadura secundaria, realizados de forma escalonada y lejos de las zonas de máxima tracción.

El espesor de la losa era tal, que el hormigón estaba capacitado por sí solo para absorber los esfuerzos cortantes, aún en las zonas más solicitadas. A pesar de ello, se doblaron los 


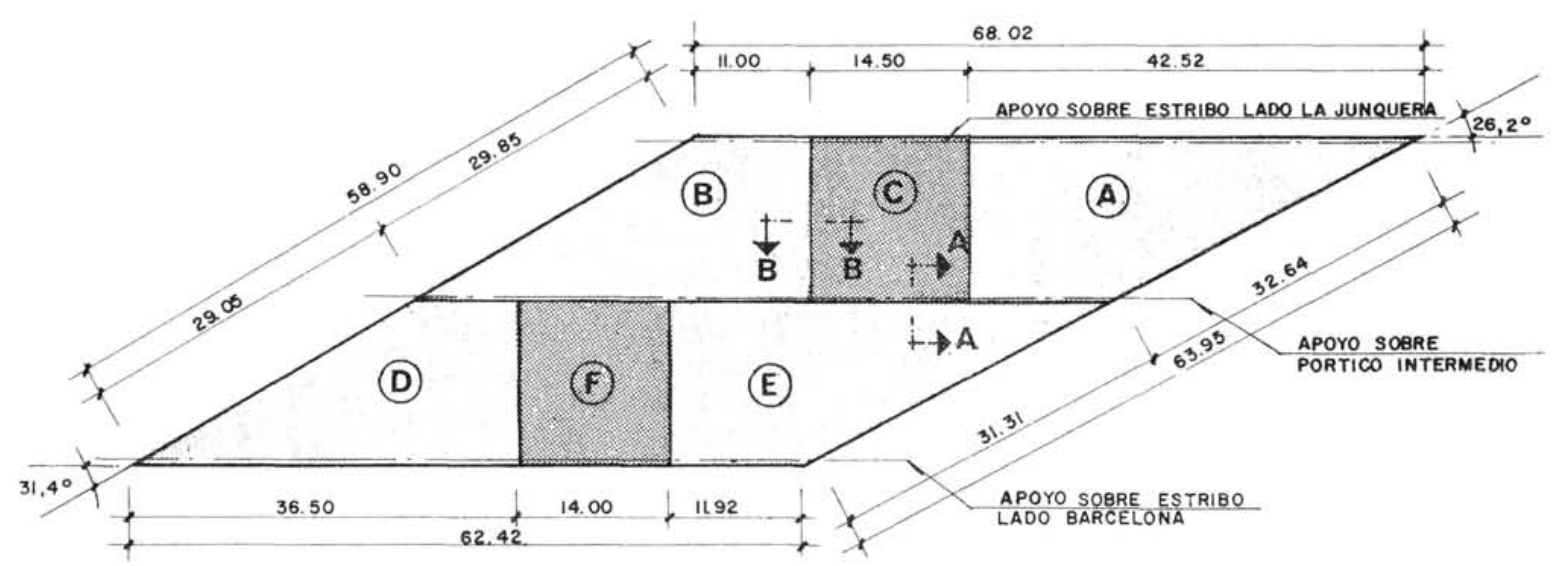

FASES DE HORMIGONADO DE LA LOSA DE TABLERO

PLANTA

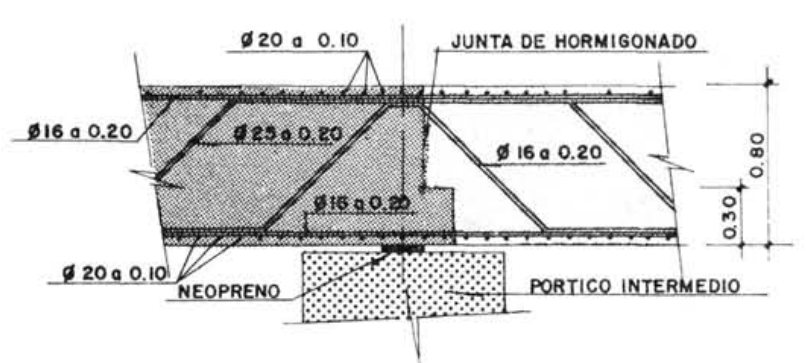

SECCION A-A ESCALA $1 / 40$

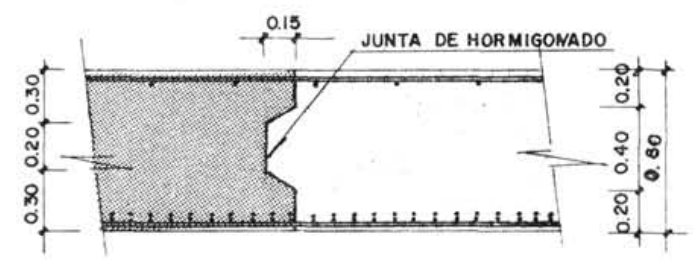

SECCION B-B

3 ESCALA $1 / 40$ extremos de las barras superiores e inferiores de la armadura principal a $45^{\circ}$, con la doble finalidad de alejar su anclaje de las zonas con fuertes tracciones y proporcionar una seguridad adicional frente al esfuerzo cortante (figuras 8 y 9 ). Las barras levantadas, dispuestas en planos sucesivos, estaban capacitadas para resistir sobradamente el esfuerzo cortante. Tal medida, que no representó apenas aumento en la cantidad de acero, dio gran seguridad, especialmente en las zonas cercanas a los apoyos de los ángulos obtusos.

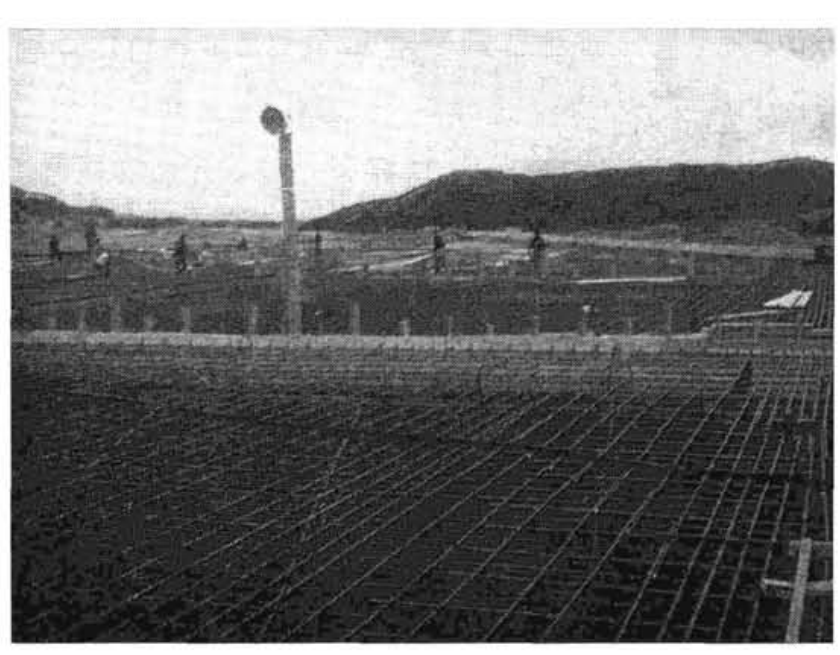




\section{Sistema de apoyos}

Se utilizaron placas de neopreno, dispuestas en línea y formando apoyos prácticamente continuos sobre los estribos y el dintel del pórtico intermedio. La separación relativa entre placas era variable, disponiéndose de forma que la tensión de compresión debida al peso propio fuese idéntica en todas ellas; quedando prácticamente a tope en los ángulos obtusos de apoyo sobre los estribos y en los extremos del pórtico central y separándose gradualmente en el resto de las zonas de apoyo, de acuerdo con la variación de las reacciones verticales.

\section{PORTICO INTERMEDIO}

En la mediana de separación de las dos futuras calzadas de la Carretera Nacional, se dispuso un pórtico para apoyo de la losa formado por once fustes de sección circular, unidos por un dintel.

Dado el carácter monolítico de la losa de tablero, se desprendió la exigencia de disponer un dintel sin juntas de dilatación, pese a su longitud, del orden de $60 \mathrm{~m}$, siendo necesario tener en cuenta en el cálculo de esfuerzos, la acción debida al acortamiento del dintel como consecuencia de las variaciones térmicas y de la retracción.

\section{CIMENTACION}

Se dispuso cimentación directa, descansando las zapatas sobre granito con tensiones inferiores a los $5 \mathrm{kp} / \mathrm{cm}^{2}$.

\section{CALCULO DE ESFUERZOS DE LA LOSA DE TABLERO}

Dada la imposibilidad de realizar analiticamente el cálculo de esfuerzos, existían únicamente dos caminos para su determinación: mediante la discretización de la losa en pequeños elementos ficticios, que permitiesen ser analizados con un computador electrónico y el ensayo de carga sobre modelos reducidos.

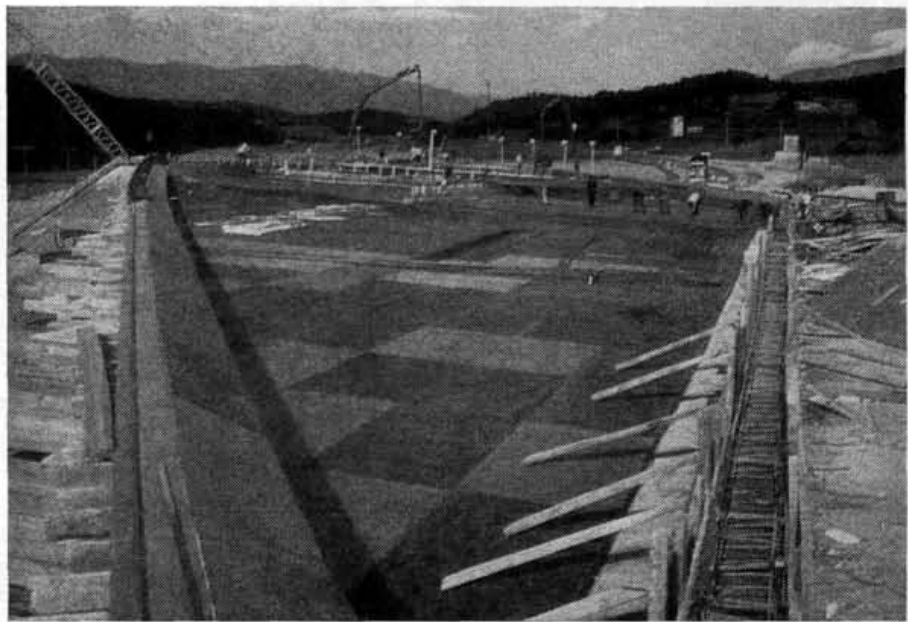

5

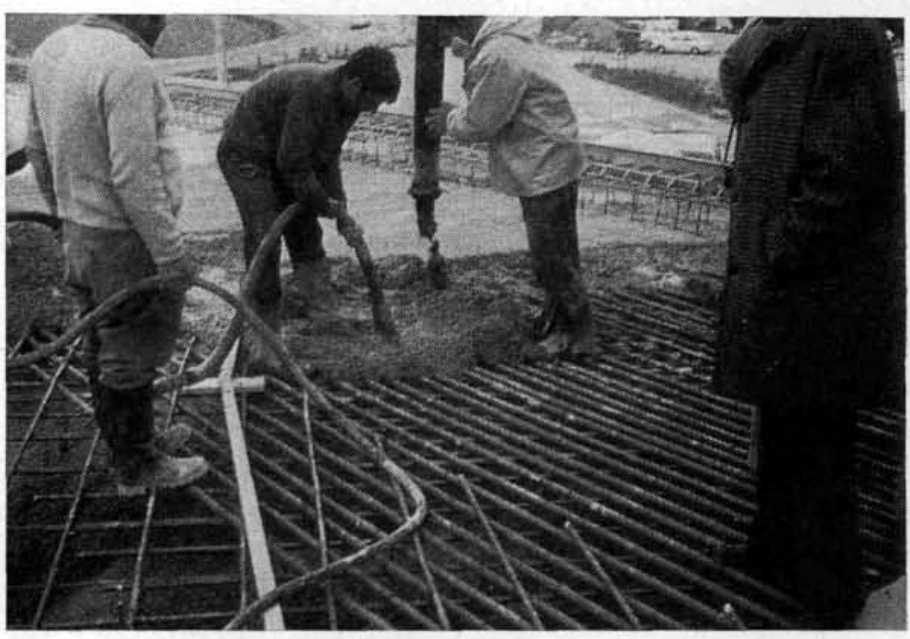

6

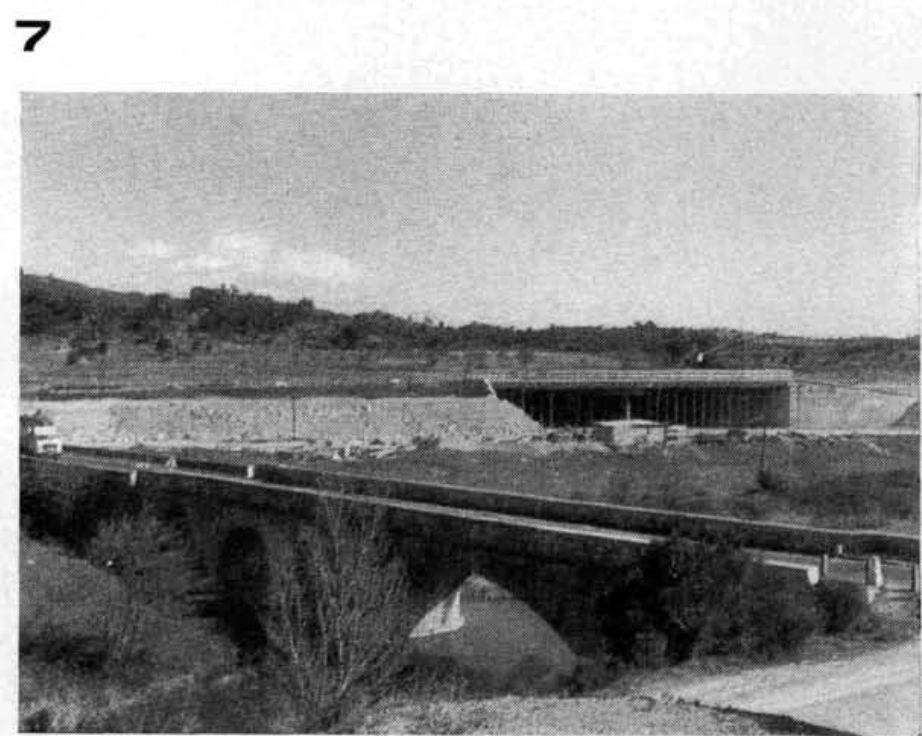




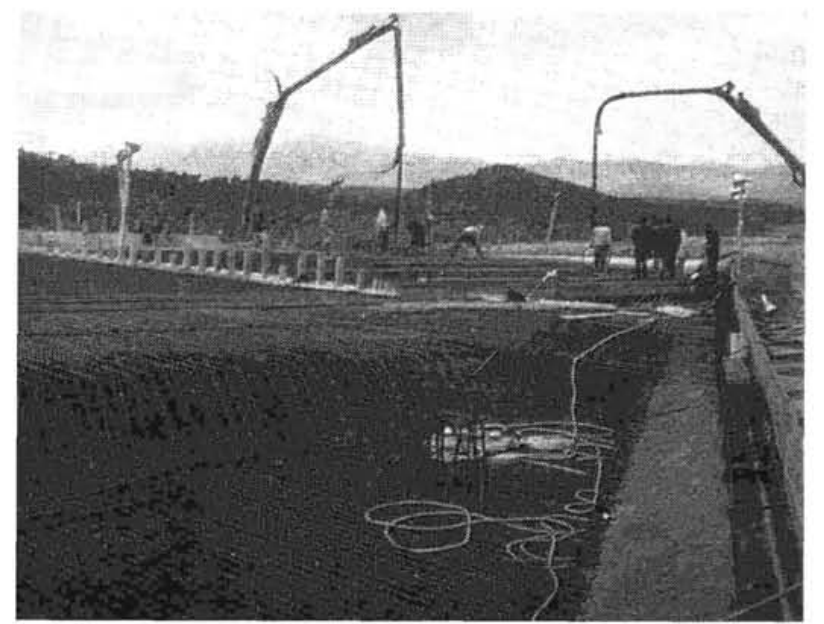

8

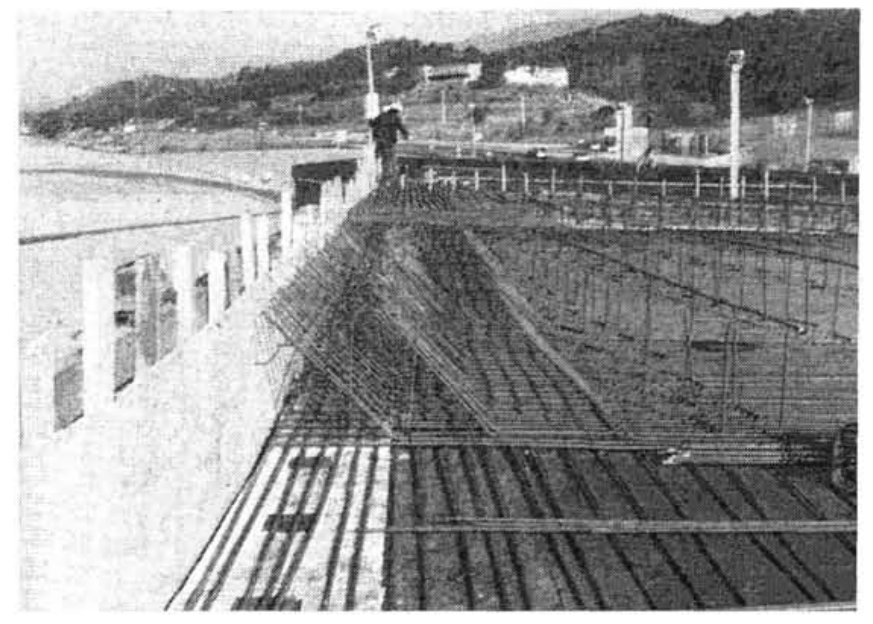

9
Inicialmente se tomaron en consideración los valores dados por la colección de tablas de Schleicher-Wegener "Placas esviadas continuas", obtenidas mediante computador electrónico, aplicando el método de las diferencias finitas, con comprobación experimental mediante modelos elásticos realizados con aluminio.

La reconocida categoría de los autores del trabajo y la difusión y el empleo de las tablas por numerosos proyectistas, fue motivo suficiente como para aceptar inicialmente los valores de la tabulación y permitir un estudio de las armaduras de la losa proyectada, no sin antes haber establecido ciertas hipótesis conservadoras para asimilar las dimensiones relativas de la losa real a la correspondiente placa virtual de la citada tabulación.

Dada la necesidad de obtener esfuerzos en puntos singulares no suministrados por la tabulación, así como el hecho de haberse adoptado en los ensayos el aluminio, con un módulo de Poisson igual a 0,34 , siendo en realidad en el hormigón 0,20 , se estimó imprescindible la realización de un ensayo sobre modelo reducido que pudiese proporcionar correctamente la información requerida para este caso concreto.

Otro procedimiento útil para la determinación de esfuerzos hubiese sido el análisis mediante computador por el método de los elementos finitos. Dada la necesidad de realizar el proyecto en escaso tiempo y al no disponer en aquellos momentos de un programa puesto a punto, no fue posible su realización.

\section{ENSAYO SOBRE MODELO REDUCIDO DE LA LOSA DE TABLERO}

Se resumen a continuación los detalles de mayor interés del ensayo. El trabajo fue realizado íntegramente en el Institut für Masivbau de la Universidad Técnica de Munich.

\section{El modelo}

El modelo se construyó a escala 1:50, reproduciendo las características geométricas del tablero, tanto en planta como en cuanto a su espesor (fig. 10). El modelo estuvo durante todo el tiempo de ejecución del ensayo en un recinto climatizado con una temperatura constante de $20^{\circ}$ y una humedad relativa del aire de $55 \%$ aproximadamente.

Debido a la imposibilidad práctica de constituir apoyos lineales continuos, se dispusieron a lo largo de cada una de las líneas de apoyo, once aparatos alineados construidos de la siguiente forma: Cada cilindro de apoyo, pegado en la parte inferior de la losa, descansaba sobre una bola, existiendo, por tanto, posibilidad de giro en todas direcciones (figura 11). En el apoyo central y en uno de los apoyos laterales se sustituyeron las bolas por anillos de medida (fig. 12) a fin de determinar con toda precisión la distribución de las reacciones de apoyo a lo largo de las líneas de soporte. Cada anillo metálico, de gran rigidez, estaba provisto de cuatro extensómetros, con lo que se deducía automáticamente la carga que sobre él incidia, sin que sus deformaciones propias acusasen un descenso 
apreciable en la placa. Con ello, las condiciones teóricas de apoyo no se alteraban y, por tanto, no aparecían esfuerzos parásitos en la placa debidos a asientos.

A fin de evitar el levantamiento de la placa en los puntos de apoyo, así como para la obtención de las reacciones de apoyo negativas, se realizó el tensado de los aparatos de apoyo contra la bancada donde se apoyaba el modelo, mediante unos dispositivos provistos de unos muelles. El ensayo se realizó posteriormente a la puesta en tensión de los apoyos, con lo que la medición no se vio afectada por los esfuerzos parásitos originados inicialmente.

Se colocaron rosetas extensométricas en dieciocho puntos escogidos en la placa del modelo, con el fin de determinar las deformaciones superficiales en tres direcciones y deducir los momentos principales en magnitud y dirección.

El proceso de medición se realizó con un sistema de registro automático de acuerdo con el esquema de la figura 13, quedando excluida la posibilidad de errores de lectura y transcripción.

Para evitar casuales errores individuales de medición se efectuó cada caso de carga por duplicado, promediándose los valores resultantes.

Los resultados del ensayo en sus diversos casos de carga quedaban resumidos en un listado, sin necesidad de realizar transcripción manual alguna (fig. 14), reflejándose no solamente las deformaciones superficiales medidas, sino también los momentos asimilables a la obra real en magnitud y dirección, con la deducción de los momentos principales.

El material escogido para este ensayo fue el yeso, que tenía la especial característica de poseer un módulo de elasticidad transversal igual a 0,215 y, por tanto, similar al del hormigón, siendo esta característica de gran importancia en placas muy esviadas, dada su influencia en la magnitud de los momentos transversales. La carga del modelo se realizó

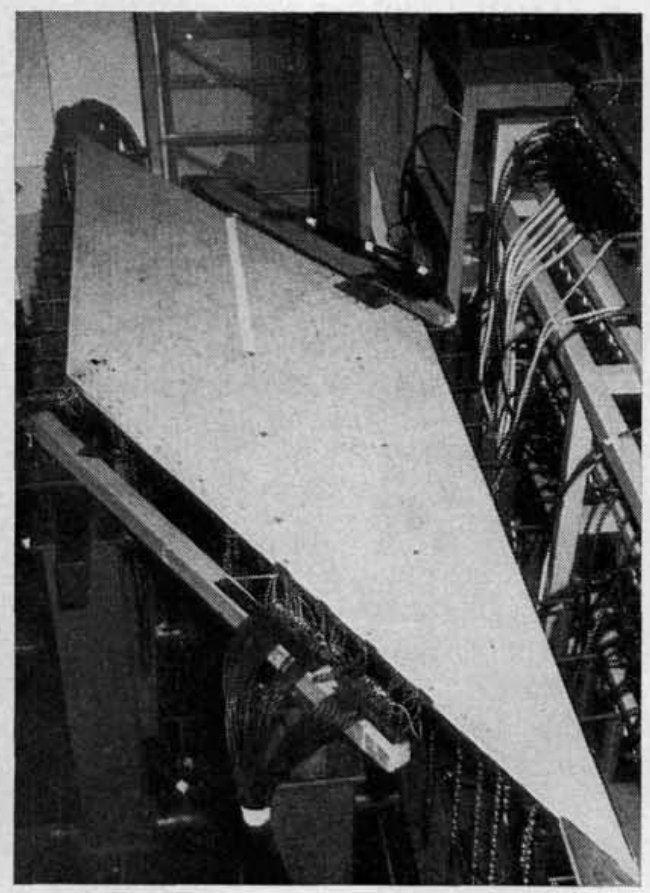

10

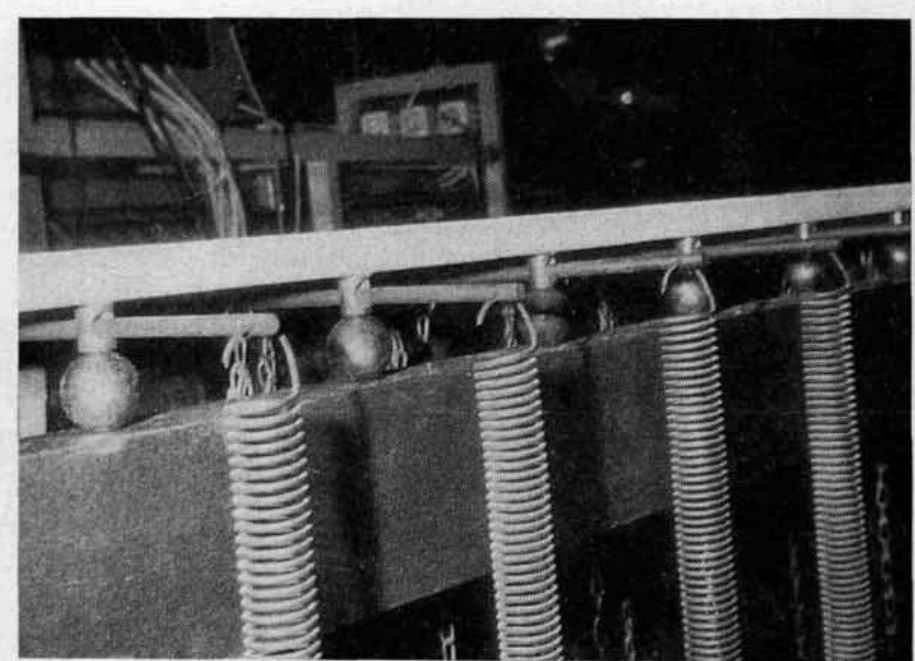

11

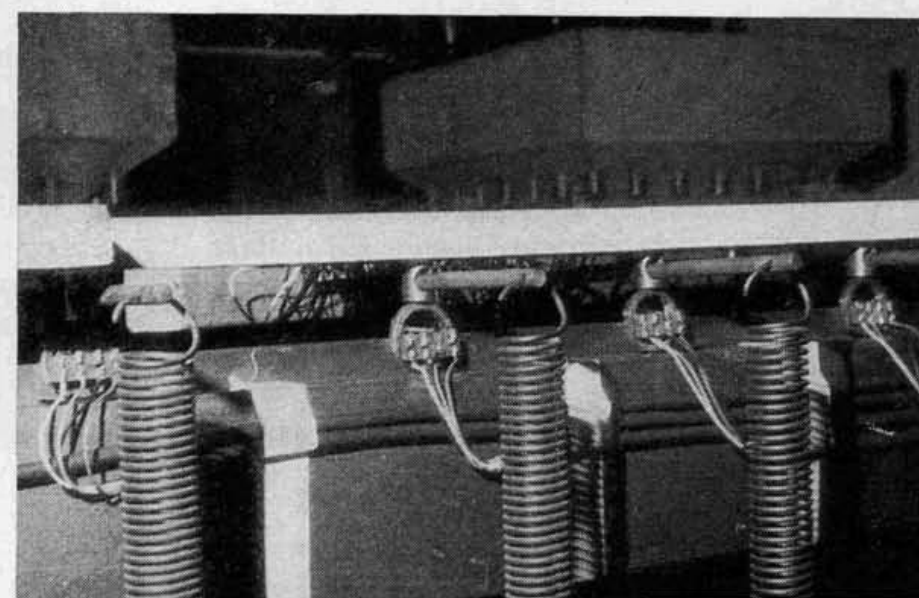




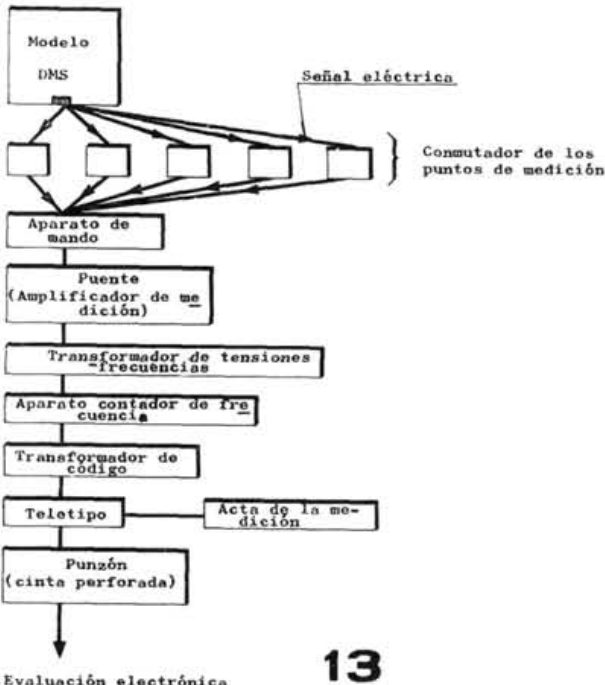

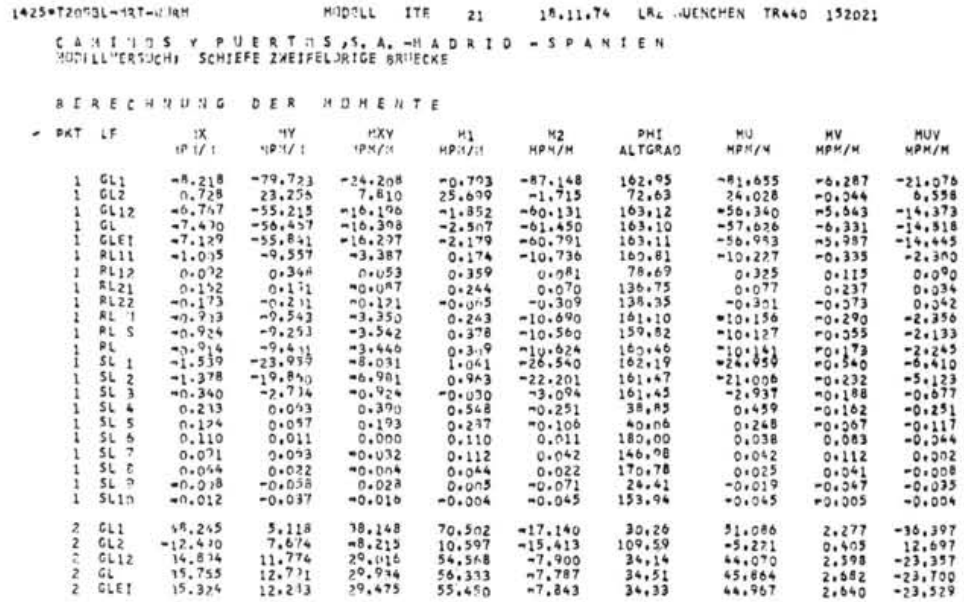

14 de tal forma que las tensiones máximas en el yeso eran del orden del $50 \%$ de la carga de rotura.

\section{Casos de carga estudiados}

Se estudiaron por separado los siguientes casos de carga:

- Carga uniforme debida a peso propio ( $\mathrm{fi}$ gura 15).
- Carga en los bordes libres (aceras y barandillas situadas en voladizos) (fig. 16).

- Sobrecarga uniformemente repartida $\left(0,4 \mathrm{Mp} / \mathrm{m}^{2}\right)$ dispuesta parcialmente en la posición más desfavorable, de acuerdo con la Instrucción Española.

- Carro de $60 \mathrm{Mp}$, con determinación de la posición más desfavorable para cada uno de los puntos estudiados (fig. 17).

El carro de la Instrucción Española se repro. dujo exactamente en cuanto a las dimensio-

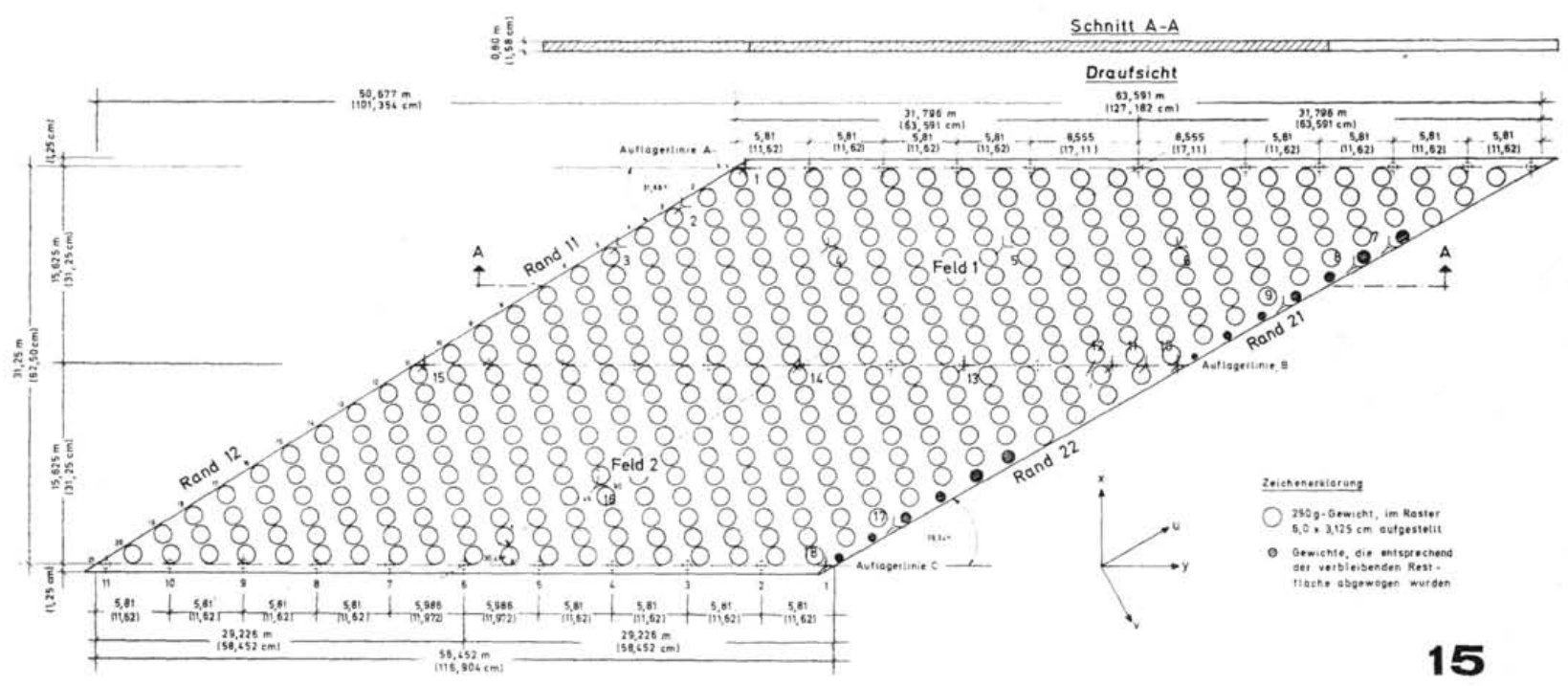



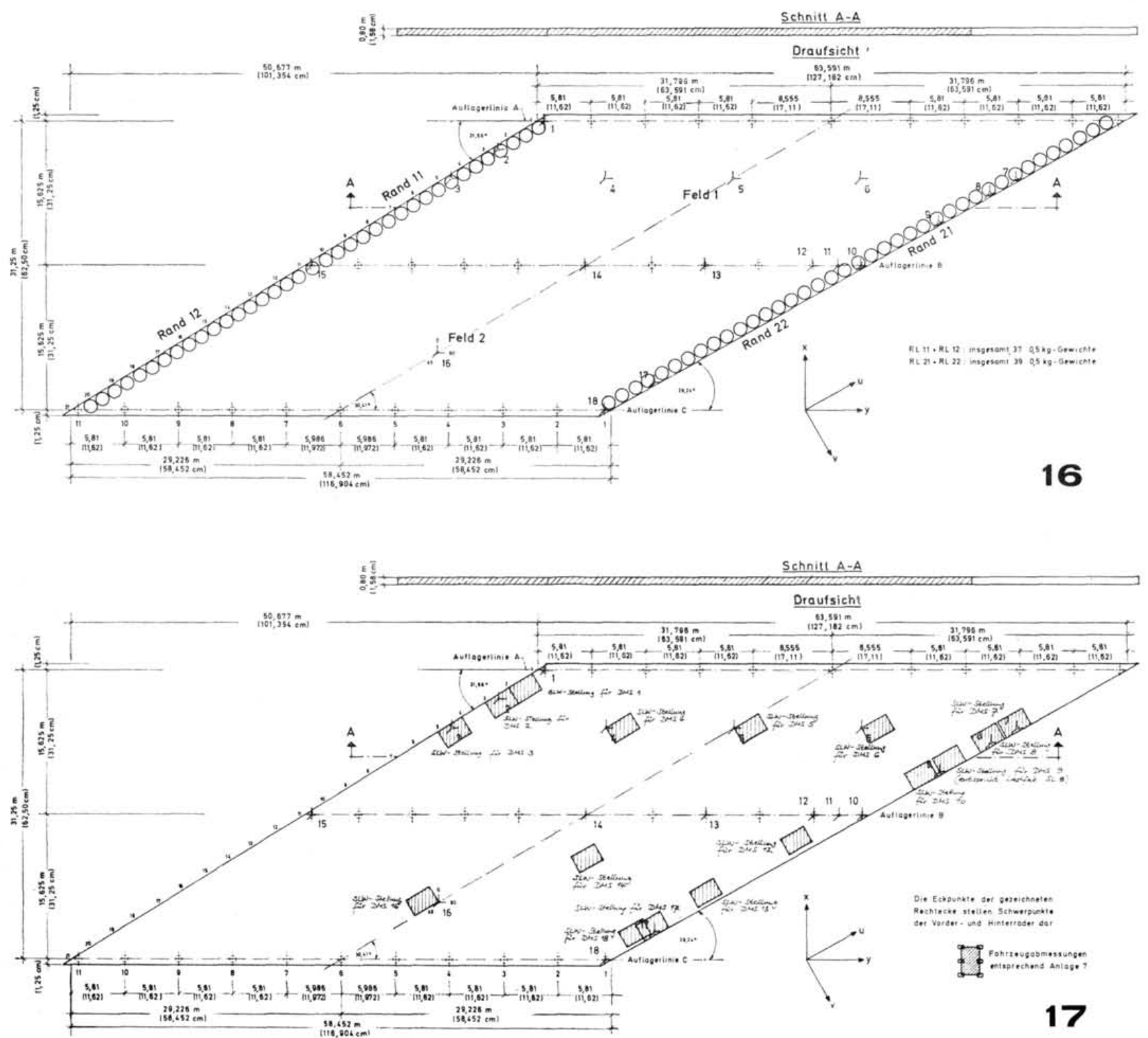

nes de las ruedas, así como la carga incidente en cada una de ellas, cuya exactitud quedaba asegurada por el esquema estático descrito en la figura 18.

El registro realizado por computador permitió la valoración inmediata de momentos y reacciones de apoyo para cada caso de carga, con la determinación de los valores máximos para la combinación más desfavorable de sobrecargas.

En la figura 19 se representan los momentos principales debidos al peso propio del tablero, y en la figura 20 los diagramas de reacciones de apoyo para el mismo caso de carga.

\section{Pruebas de equilibrio}

La comprobación de la exactitud de los aparatos de medida fue realizada mediante las siguientes pruebas estáticas:

CARRO DE $60 \mathrm{MP}$

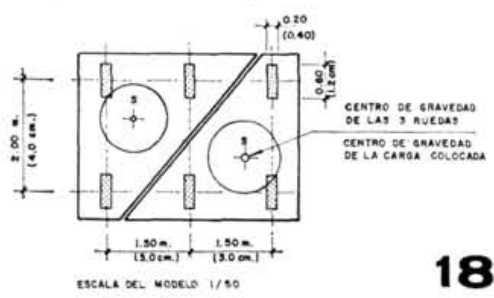



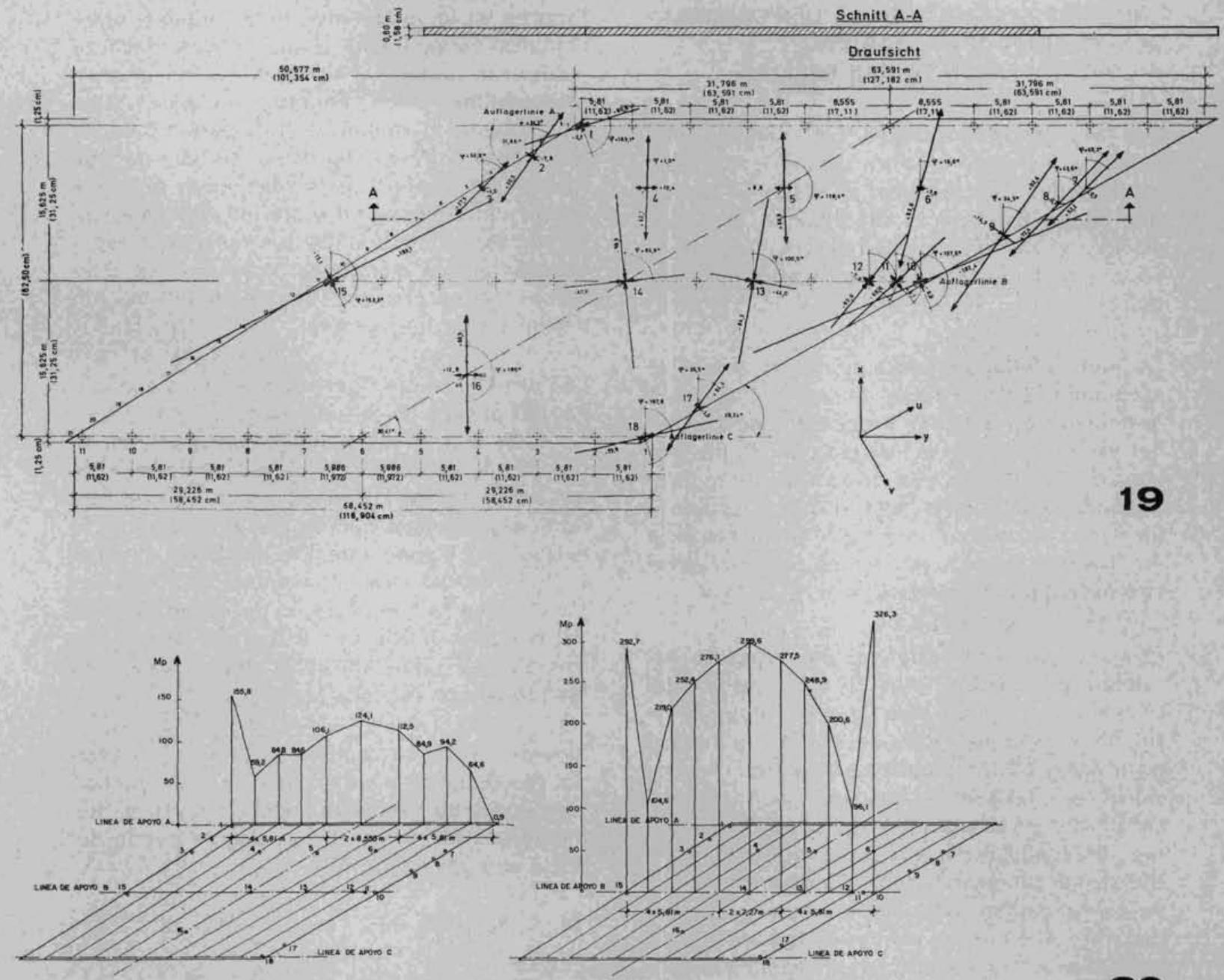

REACCiONES DE APOTO EN LA LINEA A, PARA CASO DE CARGA UNIFOPA

1. Al existir cinco puntos de medida dispuestos sobre una línea paralela a un apoyo y situada en el centro de un vano, a una distancia $\mathbf{x}_{0}$ del borde, se podía deducir el momento $\mathbf{M}_{\mathbf{x}}$ de vano de los cinco valores dados por el modelo (fig. 21) para carga uniforme, representado por la superficie comprendida entre la curva y el eje de abscisas, siendo q la carga uniforme y A la suma total de las reacciones de apoyo, el momento de vano debía cumplir la igualdad:

$$
M_{x}=A \cdot x_{0}-\frac{q \cdot x_{0}^{2}}{2}
$$

La realización de esta prueba de equilibrio, que permitía verificar conjuntamente el sistema de extensómetros para la determinación de momentos y los anillos de medición para reacciones de apoyo, arrojó diferencias inferiores al 1,7\%.

2. Para cada uno de los casos de carga (carga uniforme, carga en bordes libres y carro de $60 \mathrm{Mp}$ ) se verificó la igualdad entre la carga vertical aplicada y la suma de las reacciones de apoyo. Las diferencias observadas estuvieron comprendidas entre el 0,3 y el $1,5 \%$.

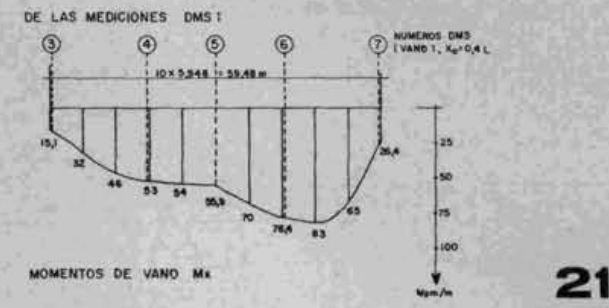




\section{CRITERIOS SEGUIDOS EN LA DISPOSICION DE ARMADURAS DEL TABLERO $Y$ COMPROBACION DE LAS MISMAS}

Con objeto de conseguir una sencilla elaboración y puesta en obra de las armaduras, se determinó la necesidad de disponer las barras según tres únicas direcciones, evitando de forma absoluta zonas de transición con armadura dispuesta en forma de abanico (figuras 22 a 25 ).

Se colocó una armadura principal según la perpendicular a la línea de apoyos, materializándose con ello la dirección fundamental del esquema de flexión exigido por la luz mecánica. Se dispuso una armadura de reparto paralela a los apoyos, con lo que el conjunto formado por ambas coincidía sensiblemente en dirección con los momentos principales en la mayor parte de la superficie de la losa.

Existía, finalmente, una tercera armadura paralela a los bordes libres en unas zonas relativamente estrechas, que dada su forma, constituian auténticas vigas de borde embebidas en la losa. Las armaduras principales - superiores e inferiores - que formaban ángulos de $60^{\circ}$ con el borde, penetraban en dichas zonas, doblándose verticalmente a $90^{\circ}$ al llegar al extremo libre de la losa y tendiendo a unirse entre ambas mediante solapes escalonados (fig. 26). La disposición de las armaduras en dichas zonas constituían un eficaz sistema resistente frente a las fuertes torsiones existentes.

La determinación de las armaduras se realizó teniendo en cuenta conjuntamente los momentos deducidos de la colección de tablas de Schleicher-Wegener y del ensayo sobre modelo reducido, siendo necesario realizar en este último unas ligeras reducciones pos- teriores en los momentos transversales, obtenidos en la vecindad de los apoyos, dada su naturaleza puntual y su condición de gran rigidez frente a los asientos verticales. Una sencilla consideración estática permitió corregir dichos valores, teniendo en cuenta que los apoyos reales en la obra eran prácticamente continuos y de material elastomérico. La correspondencia entre los resultados obteteriores en los momentos transversales obtenidos por los dos métodos de determinación de esfuerzos fue notable.

Las armaduras se comprobaron por separado en 190 puntos de la losa, teniendo en cuenta en cada uno de ellos los esfuerzos producidos por la combinación más desfavorable de las sobrecargas. Dicha hipótesis no consideraba la gran capacidad de redistribución de la estructura, puesto que los máximos momentos no existían simultáneamente en todos los puntos, con lo que el grado de seguridad real del conjunto frente a la rotura era muy superior al valor adoptado en la comprobación de las armaduras en cada punto.

La verificación se realizó mediante el método de Wood, que en su caso más general con armaduras formando un ángulo $\alpha$ entre sí, los momentos $\mathbf{M}_{\mathrm{x}}{ }^{*}$ y $\mathbf{M}_{\alpha}{ }^{*}$ de los que se puede deducir su capacidad mecánica son:

$$
\begin{gathered}
\mathbf{M}_{\mathbf{x}}{ }^{*}=\mathbf{M}_{\mathbf{x}}-\mathbf{K} \cdot \mathbf{M}_{\mathrm{xy}}-\operatorname{cotg} \alpha\left(\mathbf{M}_{\mathbf{y}} \cdot \mathbf{K}-\mathbf{M}_{\mathrm{xy}}\right) \\
\mathbf{M}_{\alpha}{ }^{*}=\frac{1}{\operatorname{sen}^{2} \alpha}\left(\frac{\mathbf{M}_{\mathbf{y}} \cdot \mathbf{K}-\mathbf{M}_{\mathbf{x y}}}{\operatorname{cotg} \alpha+\mathbf{K}}\right)
\end{gathered}
$$

siendo:

$$
\begin{aligned}
& \left(\frac{\mathbf{M}_{\mathrm{xy}}+\mathbf{M}_{\mathbf{y}} \operatorname{cotg} \alpha}{\operatorname{cotg} \alpha+\mathbf{K}}\right) \leqslant 0 \begin{array}{l}
\text { para la armadura } \\
\text { inferior } \mathrm{y}
\end{array} \\
& \left(\frac{\mathbf{M}_{\mathrm{xy}}+\mathbf{M}_{\mathbf{y}} \operatorname{cotg} \alpha}{\operatorname{cotg} \alpha+\mathbf{K}}\right) \geqslant 0 \begin{array}{l}
\text { para la armadura } \\
\text { superior. }
\end{array}
\end{aligned}
$$

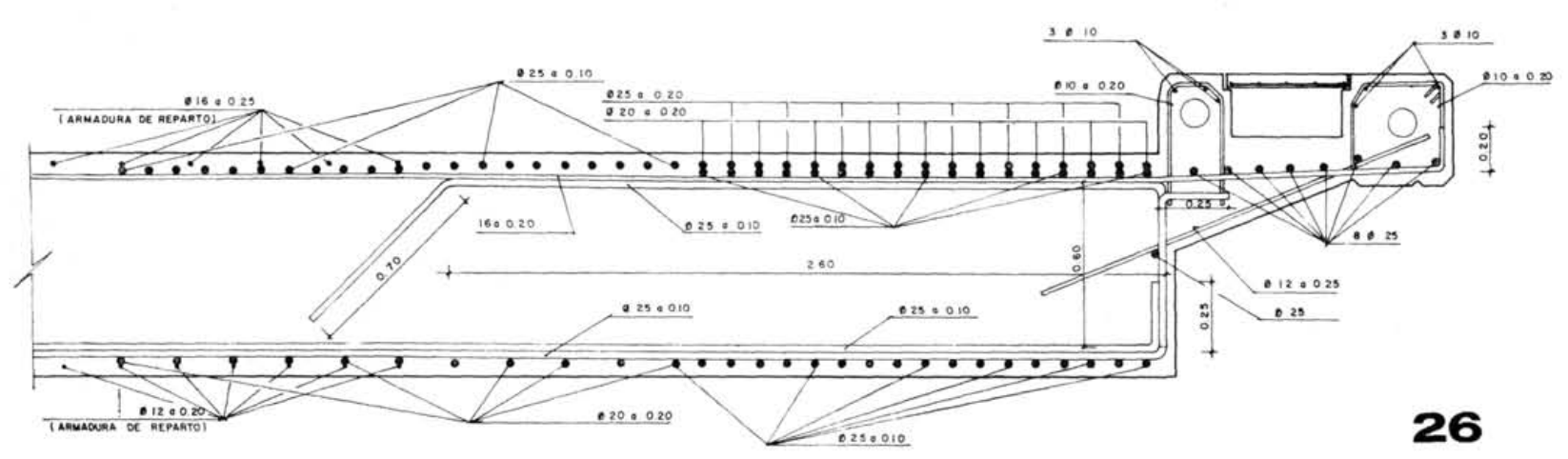


armaduras

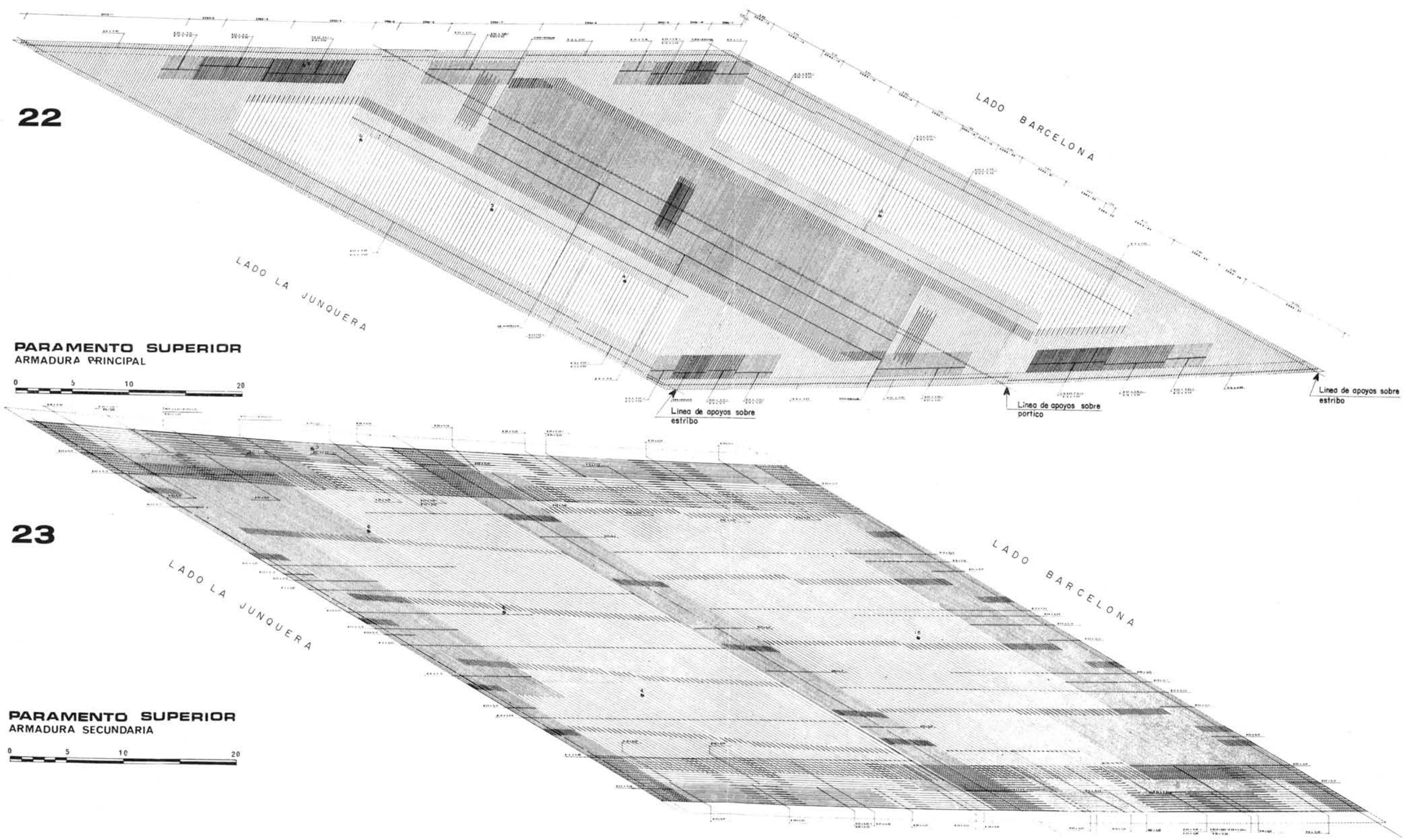


armaduras

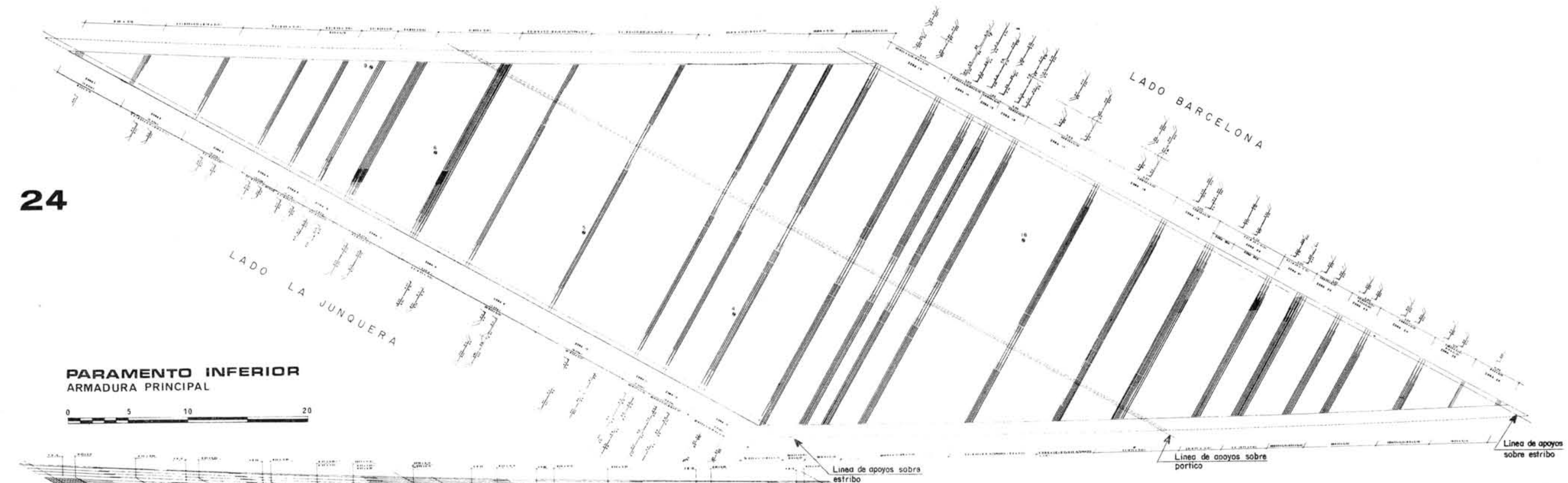

25

PARAMENTO INFERIOR DAñam
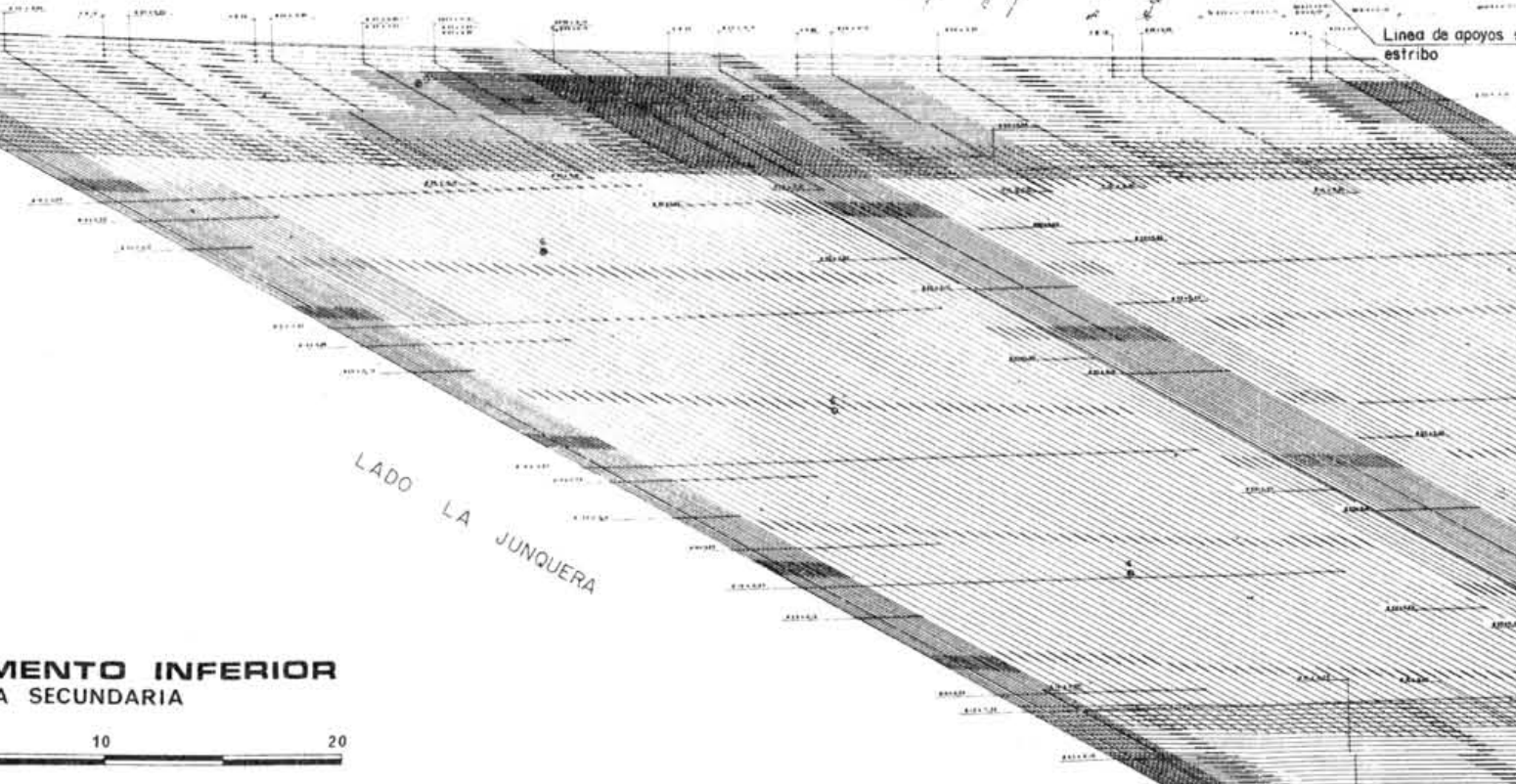


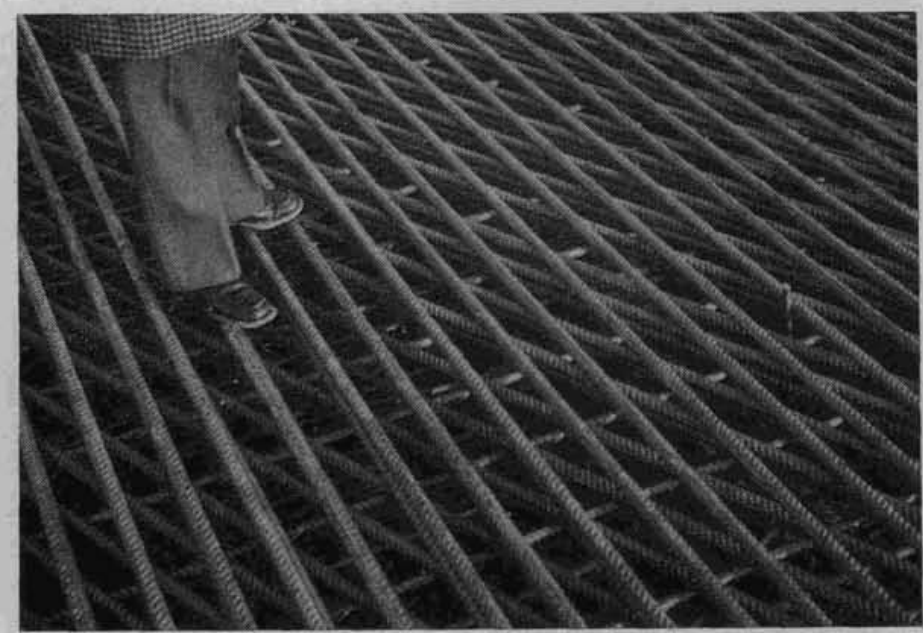

Al conocerse en cada punto los valores de $\mathbf{M}_{\mathbf{x}}$, $\mathbf{M}_{\mathbf{y}}$ y $\mathbf{M}_{\mathbf{x y}}$, $\mathbf{y}$ determinadas previamente las direcciones de las armaduras, era necesario realizar un cambio de ejes deduciendo un sistema de momentos equivalente, de forma que $\mathbf{M}_{\mathbf{x}}$ coincidiese en dirección con una de las armaduras dispuestas. El cálculo realizado con la ayuda de un minicomputador, mediante un sencillo programa elaborado especialmente para este caso, permitió una completa comprobación en todos los puntos de la losa, así como la determinación de la cuantía más económica para cada dirección de armaduras, puesto que había posibilidad, dentro de ciertos límites, de variar en cada punto la cuantía relativa de las armaduras de ambas direcciones de acuerdo con el valor de $\mathbf{K}$ escogido.

A pesar de la extraordinaria concentración de armaduras existente en zonas muy localizadas (fig. 27), la cantidad total de acero fue moderada, resultando una media del orden de $90 \mathrm{~kg} / \mathrm{m}^{2}$ de tablero, incluyendo solapes, barras inclinadas y barras verticales auxiliares para soporte de la armadura principal.

\section{TERMINACION DE LA OBRA}

Una vez descimbrada la losa de tablero, se efectuaron las correspondientes pruebas, resultando satisfactorio su comportamiento debido al peso propio y a una carga realizada mediante dos dumper de $35 \mathrm{t}$ colocados de forma que su efecto era similar al vehículo de la Instrucción Española.

Durante el descimbrado existió la oportunidad de inspeccionar detenidamente toda la superficie del intradós, comprobándose, a simple vista, la inexistencia de fisuras.

El puente fue construido en su totalidad en siete meses, transcurriendo tres meses desde el principio de la colocación de la cimbra hasta la terminación del tablero. La puesta en servicio se realizó en junio de 1975. Las figuras 28 y 29 muestran la obra terminada.

\section{COLABORACIONES}

El proyecto, realizado por el autor del presente artículo, fue llevado a cabo en la Sección de Proyectos de la empresa Caminos y Puertos, S. A., debiéndose destacar la eficaz colaboración de D. Benito Campos, D. Luis A. Serrano Blanco y D. José J. Torres.

El ensayo sobre modelo reducido de la losa de tablero fue encargado a la Universidad Técnica de Munich, en el Institut für Masivbau que dirige el Profesor Herbert Kupfer, siendo realizado por los Dipls. Ings. Daschner y Wurm. Es necesario mencionar el hecho de que el plazo de la obra limitó considerablemente el tiempo disponible para el estudio. 


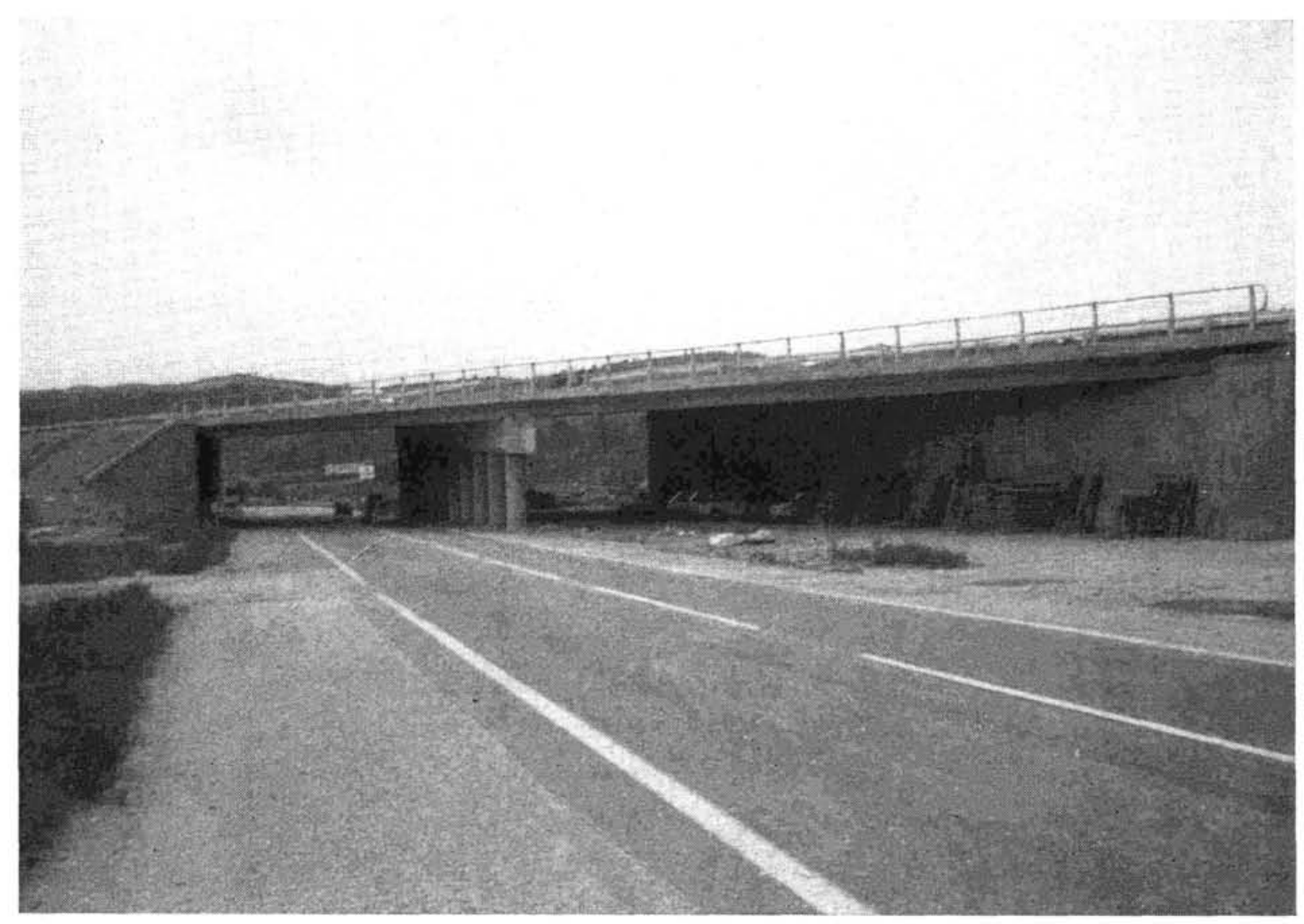

28

Gracias a la preparación técnica y organización del Laboratorio, junto con el especial interés y dedicación del Sr. Wurm, fue posible la realización del trabajo en menos de cuatro semanas, transcurridas desde la formulación del encargo, hasta la conclusión del informe con los resultados.

Debemos agradecer la excepcional intervención del Profesor Hubert Rüsch, quien se interesó vivamente por el tema y cuyos comentarios y observaciones constituyeron sabias enseñanzas aplicables a la obra, brindándose además amablemente a canalizar los trabajos del ensayo mediante sus directrices, de acuerdo con la idea perseguida y haciendo posible su eficaz realización en tan corto espacio de tiempo.

La Compañía Autopistas del Mediterráneo Concesionaria Española, S. A., bajo la dirección técnica de D. Juan M. Compte, nos dio la oportunidad de presentar el proyecto y autorizó la construcción de acuerdo con la solución propuesta. La supervisión de la obra quedó a cargo del Subdirector técnico, D. Joaquín Hernández, y del Ingeniero encargado, D. Antonio Chordá, de IBERING, entidad que desarrollaba la Dirección de Obra. Además de los controles normales de la obra, AUTOPISTAS estimó oportuno realizar una exhaustiva comprobación de los esfuerzos reales de la losa de tablero a través de la medición de deformaciones superficiales del hormigón en numerosos puntos del intradós. El trabajo, cuya dirección fue encomendada al Profesor D. José Antonio Torroja, sirvió como prueba de carga del puente, con resultados satisfactorios, como ya se ha mencionado anteriormente.

La obra fue ejecutada por la empresa Caminos y Puertos, S. A., actuando como Director de Construcción D. José Ramón Castelló. Intervino como Ingeniero Jefe de Obra D. Miguel Rodríguez, colaborando eficazmente con él D. Ricardo Castro. Deseamos expresar nuestro agradecimiento a todas las personas que han participado en la construcción, por el especial entusiasmo aportado y por su gran sentido de la colaboración. 


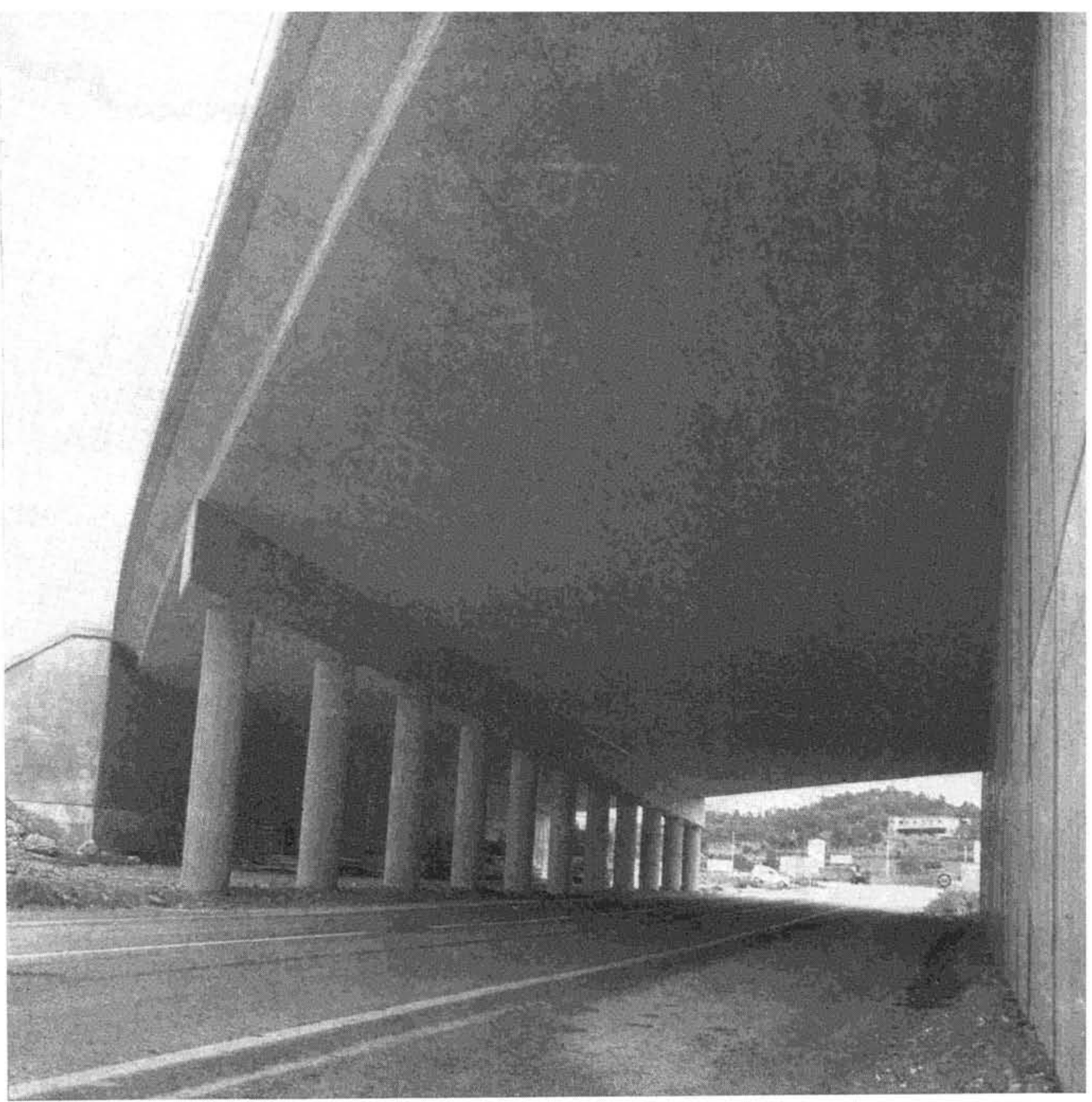

29

\section{résumé}

Pont de l'autoroute de BarceloneLa Junquera - Espagne

José Antonio Llombart.

ingénieur des Ponts et Chaussées

La construction de l'autoroute Barcelone-La Junquera a exigé la realisation d'un pont sur la Route Nationale (CN-II, km 773), au nord de Figuières (Gérone). Las caracté ristiques geométriques spéciales imposées par lintersection des deux voies de circulation et la conjonction favorable d'une série de facteurs, ont déterminé l'adoption dune solution singultere visalt a procurer ques et esthétiques qui rarement peuvent ques etressues simultanément dans cette sorte d'ouvrages.

\section{summary}

Bridge on the Motor Road Barce lona-La Junquera - Spain

José Antonio Llombart, civil engineer

With the construction of the motor road Barcelona-La Junquera it has become neces. sary to build a bridge across the National Highway (CN.II, km 773), north of Figueras (Gerona). The special geometric characte. ristics caused by the crossing of two roads and the fau by the crossing of two roads factors factors, have lead to a unique solution that provides both functional, economical as well as aesthetic qualities, a combination rarely
to be found in constructions of this type.

\section{zusammenfassung}

Brücke auf der Autobahn BarcelonaLa Junquera - Spanien

José Antonio Llombart, Zivilingenieur

Der Bau der Autobahn Barcelona-La Junquera hat es erforderlich gemacht, eine Brücke über die Reichsstrasse (CN-II, $\mathrm{km}$ 773), nördlich von Figueras (Gerona), zu konstruieren. Die besonde Kreuzung von schen Kenazichen, du ch die Kreuzung von Vereinigung einer Reihe Faktoren entstanden, haben $7 u$ einer einmaligen Lössung geführt, in der funktionale, ökonomische und ästhetische Eigenschaften, die selten in Bauten dieser Art zur gleichen Zeit vorhanden sind, vereinbart sind. 